\title{
RESEARCH OF VARIANTS TO IMPROVE STEERABILITY OF MOVEMENT OF TRAILED ASYMMETRIC HARVESTING AGGREGATE
}

\author{
Volodymyr Bulgakov ${ }^{1}$, Volodymyr Nadykto ${ }^{2}$, Semjons Ivanovs ${ }^{3}$, Janusz Nowak ${ }^{4}$ \\ ${ }^{1}$ National University of Life and Environmental Sciences of Ukraine, Ukraine; ${ }^{2}$ Tavria State \\ Agrotechnological University, Ukraine; ${ }^{3}$ Latvia University of Life Sciences and Technologies, Latvia; \\ ${ }^{4}$ University of Life Sciences in Lublin, Poland \\ semjons@apollo.lv
}

\begin{abstract}
Improvement of the stability and controllability of the movement of a trailed asymmetric harvesting machine-and-tractor aggregate is an important scientific and technical challenge. The issue how to determine the moment that stabilises the movement of this asymmetric harvesting machine-and-tractor aggregate in a horizontal plane has been theoretically investigated without increasing the overall dimensions of the trailed harvester. Analytical expressions have been compiled for the moment that unfolds the trailed harvester, and the stabilising moment that is able to return it to the state of rectilinear movement. To ensure stable movement in a horizontal plane, a series of design solutions have been proposed. Thus, the transfer of the left supporting wheel of the trailed swath reaper to the right side of the longitudinal axis of symmetry of the wheeled aggregating tractor creates conditions for increasing the stabilising moment. The use of spring compensators at the place of coupling of the swath reaper to the wheeled aggregating tractor also creates conditions for stable movement of the trailed swath reaper in a horizontal plane. The conducted experimental investigations witness about an increase in the operational indices of the experimental asymmetrical machine-and-tractor harvesting unit.
\end{abstract}

Keywords: asymmetrical aggregate, harvesting, skidding, equilibrium, parameters.

\section{Introduction}

Harvesting field crops is a stressful period of work, and it largely determines the economic indicators of the technologies [1-3]. To achieve high-quality and timely execution of the harvesting operations, both sophisticated technical means and high qualification of its operating staff are required. The trailed asymmetric aggregates find quite a wide application in harvesting cereals and grass. For instance, such aggregates (Fig. 1) are used for two-stage harvesting of grain (when mowing), mowing grass, etc. [4].

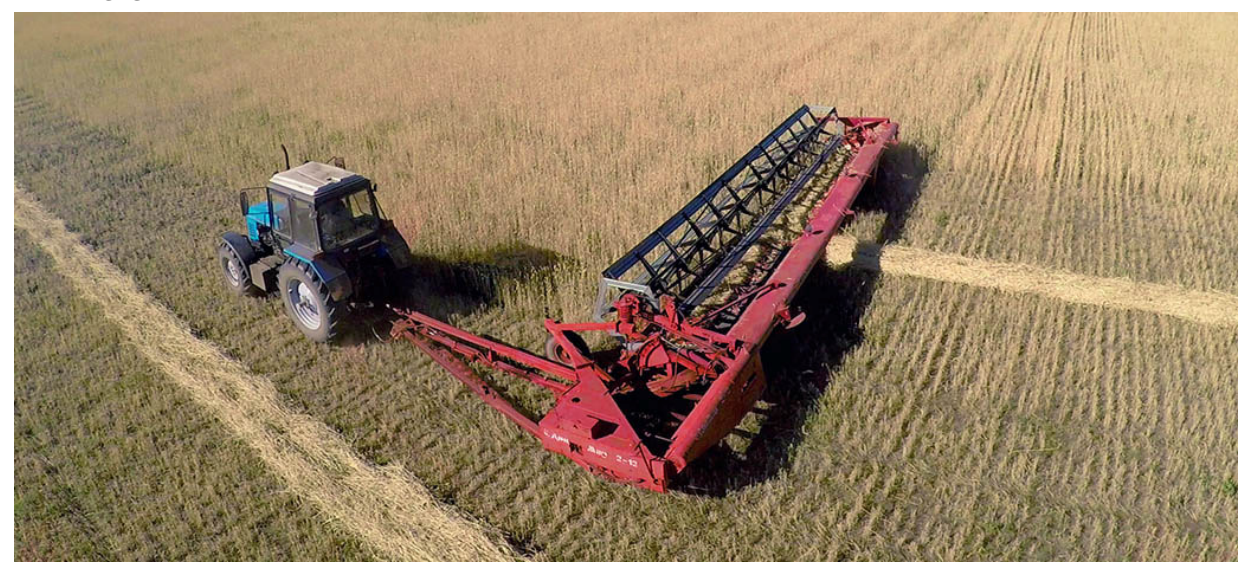

Fig. 1. Trailed asymmetrical harvesting aggregate in operation

The movement of such an aggregate has a certain specificity connected with the asymmetry of loading $[5,6]$. As a result, the rectilinear movement of the aggregate requires constant correction of the guiding wheels of the aggregating tractor. Such a situation leads to increased fatigue of the operator and raises the disruption risk of the technological process, etc.

The general theoretical foundations of the movement of asymmetric aggregates are reflected in the classic works by Gjacheva L., Vasilenko P., etc. [5-7]. The stability of the movement and improvement of the steerability of asymmetric aggregates are affected by their dynamic parameters, the presence of certain devices (for example, spring compensators, etc.), pressure in the tires of the supporting wheels, weight of the machine, etc. The impact of some factors upon the stability of the movement of an asymmetric aggregate has been considered in a number of works [4-9]. 
However, the impact of individual components of the structure, for example, the spring compensator, upon the stability of the movement, was not reviewed there.

\section{Materials and methods}

Any asymmetrically mounted trailed agricultural machine with respect to the aggregating tractor (including the swath reaper) is a dynamic system with one independent degree of freedom - the angle of rotation $\varphi$ in the horizontal plane. Let us draw an equivalent scheme of the plane-parallel movement of an asymmetrical harvesting machine-and-tractor aggregate in the form of a trailed swath reaper (Fig. 2). Here the aggregating tractor is not shown, only a point $O$ on its hitch device, to which the swath reaper is attached, is indicated (Fig. 2).

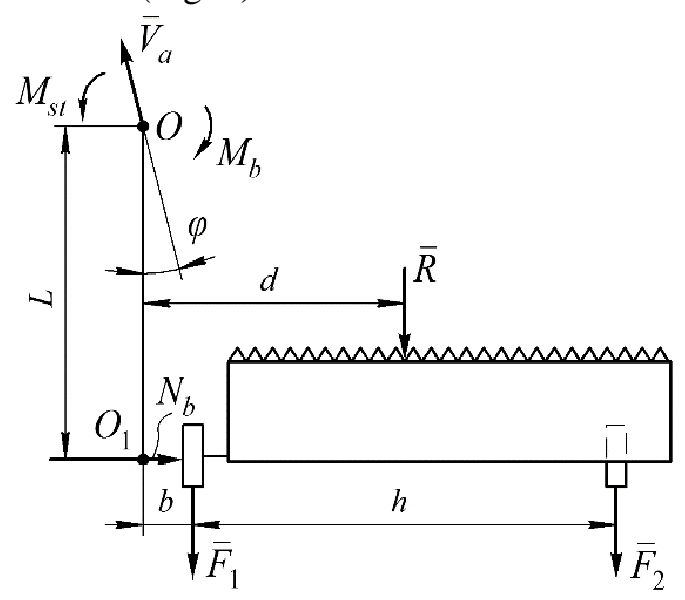

Fig. 2. Equivalent scheme of plane-parallel movement of asymmetric harvesting aggregate

The swath reaper has a hitch bar 7 with a length $L$, two supporting wheels (in some cases, dual wheels can be installed on the left side of the swath reaper), the distance between which is indicated by $h$. The conditional axis of the supporting wheels of the swath reaper crosses the hitch bar at the point $O_{1}$. The distance from the point $O_{1}$ to the longitudinal axis of the left supporting wheel is indicated by $b$.

For such an asymmetric machine-and-tractor aggregate, the equilibrium position of its trailed asymmetrically installed swath reaper is determined at each moment of time by the ratio of the unfolding $M_{b}$ and the stabilizing $M_{s t}$ moments acting relative to the attachment point $O$ of the swath reaper to the aggregating tractor (Fig. 2). Let us use the data presented in the equivalent scheme (Fig. 2) and determine the values of the unfolding $M_{b}$ and stabilizing $M_{s t}$ moments acting upon the trailed asymmetrical swath reaper. We will have:

$$
M_{b}=R \cdot d+F_{2} \cdot(h+b)+F_{1} \cdot b,
$$

and

$$
M_{s t}=N_{b} \cdot L,
$$

where $R$-resistance force resulting due the action of the loads that arise during the execution of the technological process (mowing and collecting the grain-stem massive);

$F_{1}, F_{2}$ - rolling resistance forces of the left and the right supporting wheels of the swath reaper;

$N_{b}$ - lateral reaction of the soil upon the supporting wheels of the swath reaper due to their skidding in the direction of the axes applied to the left supporting wheel;

$L, d, h$ and $b$-structural dimensions that determine the arrangement of these external forces acting upon the swath reaper.

Since the stabilising moment $M_{s t}$ arises due to the emergence of the unfolding moment $M_{b}$, then, because of the deformation of the soil under the left and the right supporting wheels of the trailed swath reaper, it is impossible to eliminate completely its angular deviation in the horizontal plane. The zero value of the specified angular parameter $\varphi$ should be considered as a statistically random value. 
Besides, a necessary condition is that at each moment of time the deviation of the swath reaper from the direction of its movement, determined by the deviation of the vector $V_{a}$, should be as small as possible. In addition, the stabilising moment $M_{s t}$ must have an appropriate value.

Experimental studies were conducted according to the standard test methods [10-14].

\section{Results and discussion}

From the analysis of expressions (1) and (2) it follows that an increase in the stabilising moment $M_{s t}$ is possible in the case of a significant increase in length $L$, i.e. elongation of the hitch bar of the trailed swath reaper (Fig. 2). However, the increase in the length of the hitch bar of the trailed swath reaper unambiguously leads to an increase in the length of the entire harvesting machine-and-tractor aggregate. This factor cannot be ignored, since at certain correlations of the dimensions $L$ and $h$ the aggregating tractor may not carry out its own steerability as part of a particular trailed machine-andtractor aggregate. On the whole, this will lead to an undesirable increase in unproductive losses of the shift time and other negative phenomena.

Consequently, in this case, there remain other ways of search how to reduce the value of the unfolding moment $M_{b}$. As it is obvious from equation (1), this can be achieved in two ways. The first way is to reduce the rolling resistance forces of the left $F_{1}$ and the right $F_{2}$ supporting wheels of the trailed swath reaper. Thus, it is known from the theory of the tractor that the values of the indicated rolling resistance forces can be determined with sufficient accuracy for practical calculations using the following expressions:

$$
F_{1}=f \cdot G_{1},
$$

and

$$
F_{2}=f \cdot G_{2},
$$

where $f$-rolling resistance coefficient;

$G_{1}, G_{2}$ - he gravity forces of the swath reaper, which fall onto its left and the right supporting wheels, respectively.

Further, when substituting expressions (3) and (4) into expression (1), one can see that it is possible to achieve a reduction in the value $M_{b}$, provided that the considered forces $F_{1}$ and $F_{2}$ are reduced, which will be determined by a decrease in the operating weight of the entire swath reaper. However, it is not always possible to do this, since reduction in the weight of the asymmetric trailed machine is a potential cause of the less stability of its movement both in a horizontal and a longitudinal-vertical plane.

The second way how to reduce the unfolding moment $M_{b}$ is to reduce the arms of the action of the forces $F_{1}$ and $F_{2}$. In this case these are the linear dimensions $b$ and $h$, shown in Fig. 2. As it can be seen from the presented force diagram, the solution of this task is possible not only by reducing the value of $b$ to zero, but also by transfer of the left supporting wheel of the trailed swath reaper to the right side relative to the axis $O O_{1}$, in general. In such a case expression (1) will have the following form:

$$
M_{b}=R \cdot d+F_{2} \cdot(h+b)-F_{1} \cdot b .
$$

When analysing expression (5), we see that the rolling resistance force of the left wheel $F_{1}$ should not decrease, but, on the contrary, it should increase. The moment created by this force, equal to $\left(F_{1} \cdot b\right)$, in this case will already be a stabilising one.

For the trailed swath reapers of the type ZVP-6 the left supporting wheel is installed to the right of the hitch bar, which, as the theoretical analysis presented above shows, is not desirable. In addition, as shown by the results of the experimental investigations, carried out by us during the work on lowcohesive or wet soils, characterised by low resistance to lateral displacement, or on any soils with an agricultural background humidity of $20 \%$ and higher, the deviation angle of such aggregates from the longitudinal axis of symmetry of the aggregating tractor may reach about $15^{\circ}$.

The presence of the indicated angle always leads to decomposition of the resistance force of the machine into two components: the longitudinal and the transverse one. The latter creates a moment 
which tries to turn the aggregating tractor clockwise in a horizontal plane. Under the conditions of the experiments the deviation angle from the course of the source of energy varied from $3^{\circ}-$ at a soil moisture of $20 \%$, to $5.1^{\circ}$ - at an agrofone humidity of $26 \%$ [4]. To align the movement of the asymmetrical machine-and-tractor aggregate, the operator constantly installs the frontal steering wheels of the aggregating tractor at a corresponding angle to the direction of its movement. As a result, the driven wheels slipped, squeezing the soil with their protectors sideways. This causes increased losses of power for overrolling; besides, of the aggregating tractor and the losses of power for implementation of the technological process. Due to the movement of the aggregating tractor at a constant angle to the theoretically possible rectilinear movement, its tractive resistance also increased. It was established that under the field conditions the value of the increase in this parameter may reach $27 \%$. In an adequate manner, as a result of this, skidding of the driving wheels of the aggregating tractor is increased by a corresponding value, which leads to additional fuel consumption.

This problem can also be solved by using spring compensators. As the results of the experimental investigations conducted by us showed, it is the spring compensators that provide a possibility to use them rather efficiently when working at increased speeds. In addition, it is possible to install such spring compensators in different ways. In the first case the spring compensator can be installed to the left of the hitch bar. With its one end it is mounted on the trailer device of the aggregating tractor, and with the other end on the aggregated trailed swath reaper. Structurally, the indicated compensator is a reaction thrust 2 with the spring 3 , which is constantly operating on compression (Fig. 3).

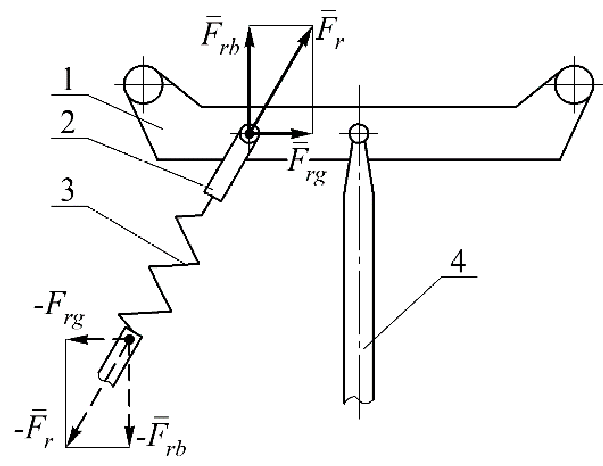

Fig. 3. First version of installation of spring compensator on trailed asymmetric harvesting aggregate with its left-side arrangement

Thus, with one end the thrust 2 is connected to the frame of the trailed swath reaper (in Fig. 3, position 4 indicates its hitch bar), and with the other - to the hitch bracket 1 of the rear hitch mechanism of the aggregating tractor. During the working movement, the unfolding moment $M_{b}$, tending to turn the trailed swath reaper clockwise, compresses the spring 3 , in which the force $\bar{F}_{r}$ arises, which can be presented as two components - the longitudinal $\bar{F}_{r b}$, directed parallel to the longitudinal axis of the aggregating tractor and the transverse $-\bar{F}_{r g}$ one. These forces are transferred to the point of attachment of the spring compensator on the trailed swath reaper with opposite signs. The longitudinal component $-\bar{F}_{r b}$ creates a stabilizing moment $M_{s t}$ that tends to align the trailed swath reaper by turning it counter clockwise. Although, the transverse component $-\bar{F}_{r g}$ of the force to a certain extent prevents this. However, since the value of the transverse force $-\bar{F}_{r g}$ is significantly less than the value of the force $-\bar{F}_{r b}$, we generally have a positive result: deviation of the header in the horizontal plane from the action of the unfolding moment $M_{b}$ in the presence of the spring compensator is smaller than at its absence. It should also be emphasized that the components of the spring force $\bar{F}_{r}$ and its components $\bar{F}_{r b}$ and $\bar{F}_{r g}$ act upon the aggregating tractor in a similar way. The first component creates a moment that is trying to turn the tractor clockwise, and the second in the opposite direction. In addition, the value of the force $\bar{F}_{r b}$ is greater than the value of the force $\bar{F}_{r g}$, but the arm on which it creates the moment is much less. As a result, the impact of the longitudinal component $\bar{F}_{r b}$ upon the aggregating tractor is practically negligible. As regards the moment from the action of the force $\bar{F}_{r g}$, it is somehow compensated by the moment from the action of the transverse component of that resistance force, with which the swath reaper acts upon the aggregating tractor through the hitch bar. 
Consequently, the greater the rigidity of the spring 3 of the compensator, the larger the unfolding moment $M_{b}$ that the trailed swath reaper can handle. However, as it turned out from the results of the experimental field studies conducted by us, at a too great unfolding moment $M_{b}$ and at a too small its value (at considerable rigidity of the spring 3, used in the compensator), there are also some negative phenomena. Thus, in the first case an effect of the so-called rigid semi-mounted attachment of the trailed swath reaper to the aggregating tractor takes place. In the second case an additional deviation angle of the swath reaper appears in a horizontal plane.

A variation of the method for improving the stability of the movement of asymmetrically attached trailed machines is the use of a spring compensator located not outside, but inside the swath reaper design (Fig. 4). In this case an extension spring is used, and in this compensator it is installed with a pretension. In principle, the impact of such a compensator upon the trailed swath reaper and the aggregating tractor is the same as that provided by the external compensator discussed above.

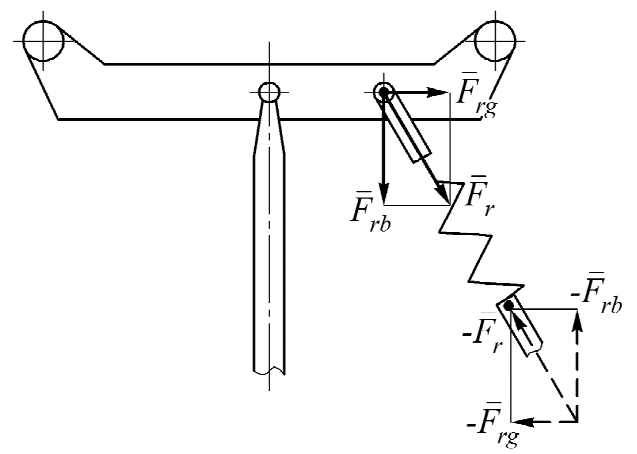

Fig. 4. Second version of installation of spring compensator on trailed asymmetric harvesting unit with its right-side arrangement

It was found out that, increasing pretension of the cable of the compensator, the deviation angle of the swath reaper in a horizontal plane decreases. This theoretical conclusion is confirmed by experimental tests. It is also possible to reduce the pretension value of the compensator spring with the same changing effect of the deviation angle of the trailed swath reaper by mounting the compensator parallel to the hitch bar. Such a constructive option, as the tests showed, presents a positive variant, yet its implementation is accompanied by certain difficulties. They are connected with a need to make and install an additional cross-bar allowing attachment of the spring compensator cable parallel to the hitch bar of the swath reaper.

When the speed of the movement of the harvesting machine-and-tractor aggregate is increased, the value of the deflection angle of the trailed swath reaper increases. At the same time, an opposite effect was obtained: increasing the speed of the movement of the asymmetric trailed machine from 5.95 to $7.10 \mathrm{~km} \cdot \mathrm{h}^{-1}$, the deviation angle decreased from $4.8^{\circ}$ to $4.3^{\circ}-$ on chernozem (black soil), and from $8.0^{\circ}$ to $7.2^{\circ}$ - on sandy loam soil. Indeed, an increase in the speed of the movement of the asymmetric harvesting machine-and-tractor aggregate is always accompanied by an increase in its tractive resistance. And since this is so, then, as a result of such a change in the speed limit, an increase in the deviation angle of the machine in a horizontal plane should be expected.

Analysis of the obtained results allows a conclusion that there are technical conditions to prevent deviation and to increase the steerability of the trailed asymmetric machine-and-tractor harvesting aggregate. Besides, such a phenomenon should be taken into account as lateral skidding of the supporting wheels of the trailed harvester under the impact of the elastic properties of their tires and soil deformation. This will provide even more accurate results on the stability and steerability of the movement of such aggregates.

In this case, an extension spring is used, and in this compensator it is installed with a pretension. In principle, the effect of such a compensator on the trailed swathe reaper and the aggregating tractor is the same as that provided by the external compensator discussed above.

It was found that, increasing the spring pretension of the compensator, the deviation angle of the reaper in a horizontal plane decreases according to the non-linear law. We managed to confirm this theoretical result by experimental studies. 
During the research the force in the spring of the swathe reaper compensator was set to 0.10 and $20 \mathrm{kN}$. In all three options of setting this harvesting unit, it moved at the same speed, equal to $2.5 \mathrm{~m} \cdot \mathrm{s}^{-1}$. The soil moisture in a layer of $0-15 \mathrm{~cm}$ was equal to $22.3 \%$, and the density $-1.1 \mathrm{~g} \cdot \mathrm{cm}^{-3}$.

As a result, the following was established. At the absence of the spring pretensioning of the swathe reaper compensator, the angle of its deviation from the direction of the movement of the harvesting aggregate was $7^{\circ}$ (Fig. 5).

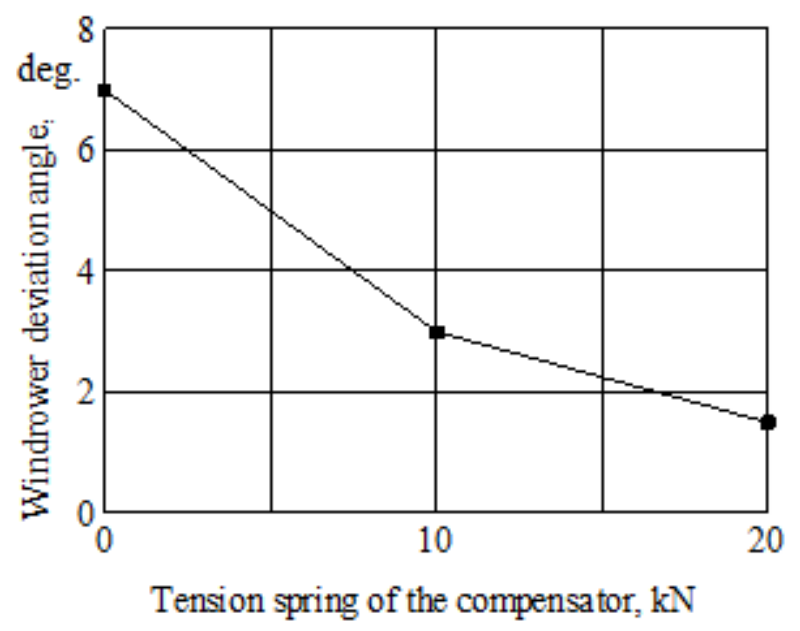

Fig. 5. Impact of compensator extension spring upon deviation angle of swathe reaper

When the compensator spring of the reaper was pretensioned with a force of $10 \mathrm{kN}$, its deviation angle decreased by a factor of 2.3 (from 7 to $3^{\circ}$ ). A subsequent increase in the pretension of the compensator spring to $20 \mathrm{kN}$ led to a further decrease in the deviation angle of the swath reaper, but only by 1.6 times. This result indicates that the intensity of the decrease in the angle of deflection of the swath reaper decreases, when the pretension of the cable of its compensator decreases.

To reduce the preload tension of the compensator spring with the same effect by changing the deviation angle of the trailed header, you can also install the compensator parallel to the header (Fig. 6). It is possible to reduce the value of pretension of the compensator spring with the same effect as by changing the deviation angle of the trailed swath reaper also by installing the compensator parallel to the hitch bar of the reaper (Fig. 6).

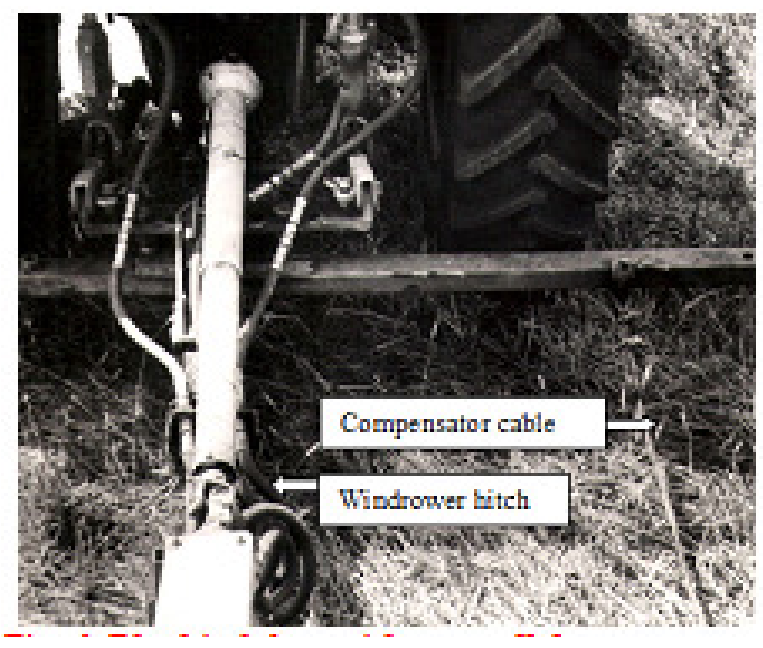

Fig. 6. Hitch bar with parallel compensator

Under the field conditions this variant of the harvesting machine was compared with two more variants. According to the first of them, the swath reaper was without a compensator at all. In the second version, it was equipped with a compensator according to the scheme shown in Fig. 4. In this case pretension of the compensator spring was equal to $10 \mathrm{kN}$. 
In the process of the research, the speed of the movement of each aggregate was set equal to 2.0; 2.5 and $3.0 \mathrm{~m} \cdot \mathrm{s}^{-1}$.

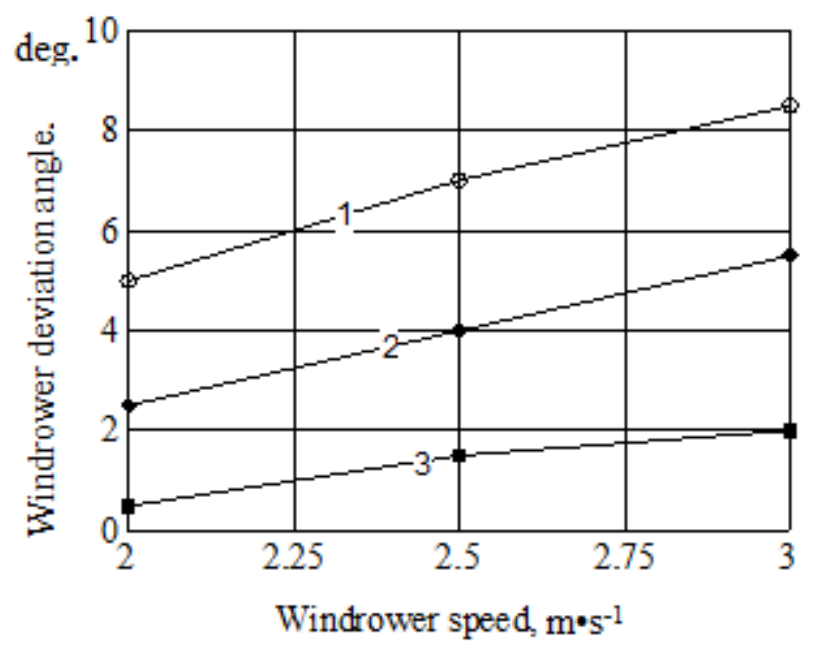

Fig. 7. Impact of harvester speed upon its deviation angle: 1 - swath reaper without a compensator; 2 - swath reaper with a non-parallel compensator; 3 - swath reaper with a parallel compensator

As it follows from the analysis of the obtained research results, an increase in the speed of the movement of the harvesting aggregate in all adjustment variants of the swath reaper leads to an increase in the angle of its deviation in a horizontal plane (Fig. 7). As it should be expected, the greatest deviations were obtained at the absence of a spring compensator (Fig. 7, Curve 1). On the contrary, the smallest deviations of the swath reaper occur, when the spring of its compensator is located parallel to the direction of the movement of the harvesting aggregate (Fig. 7, Curve 3).

The theoretical and experimental investigations, as well as comprehensive analysis of the obtained results, allow drawing a conclusion that there are technical conditions how to prevent skidding and improve the steerability of the trailed asymmetric harvesting machine-and-tractor aggregate. In addition, it is necessary to take into account such a phenomenon as lateral skidding of the supporting wheels of the trailed harvesting machine under the impact of the elastic properties of their tires and soil deformation. This will make it possible to obtain even more accurate results about the stability and steerability of the motion of such aggregates.

In order to analyse the stability of the movement of the asymmetrical trailed harvesting aggregate, it is necessary to make the right choice of the estimated parameter. When conducting theoretical research of the behaviour of the dynamic system in this capacity, application of the well-known criteria by Lyapunov, Raus-Hurwitz, Nyquist, Mikhailov or the simplified criteria by Gyachev and others in this case is not purposeful. This is explained by the fact that the trailed swath reaper, asymmetrically mounted on the aggregating tractor, as a model of a physical pendulum, is asymptotically stable but the aggregate itself, as part of the aggregating tractor and an asymmetric trailed machine, is, on the contrary, an unstable dynamic system. Therefore, application of the indicated criteria can be replaced by the "practical" stability of the movement of the machine-andtractor aggregate additionally considered by us. Since the asymmetrically trailed swath reaper can affect the source of power so that the operator is forced to exercise a corresponding control action, justification of the parameters of the harvesting machine-tractor aggregate cannot be complete without an analysis of the steerability of its working movement, which will be a subject of our further study.

\section{Conclusions}

An increase in the speed of the movement of the asymmetric harvesting machine-and-tractor aggregate is always accompanied by an increase in its tractive resistance and, accordingly, an increase in the deviation angle of the machine in a horizontal plane. To reduce the deviation angle of the swath reaper in a horizontal plane, the installation scheme of the spring compensators on the hitch device is justified. 


\section{References}

[1] Rademacher T. Trends in the Process Technology of Grain Crop Harvesting. Agritechnica, No 6, 2003, pp. 362-368.

[2] Shinners K., Bennett R., Hoffman D. Single- and two-pass corn grain and stover harvesting. Transactions of the ASABE. Vol.55 (2), 2012, pp. 341-350.

[3] Löttjönen T., Mikkola H. Three mechanical weed control techniques in spring cereals Agricultural and Food Science in Finland. Volume 9, Issue 4, 2000, pp. 269-278.

[4] BulgakovV., Zaryshnyak A., Beloev H., Ivanovs S. Investigation of amplitude-frequency characteristics of disturbing and control impacts of asymmetric swath header machine-and-tractor aggregate. Engineering for rural development, proceedings, Vol. 17, 2018, pp. 221-226.

[5] ГячевЛ. Stability of the movement of agricultural machines and aggregates (Устойчивостьдвижениясельскохозяйственныхмашиниагрегатов).

Mechanicalengineering,Moscow, 1981. 206 p. (In Russian)

[6] Bulgakov V., Pascuzzi S., Nadykto V., Ivanovs S. A mathematical model of the plane-parallel movement of an asymmetric machine-and-tractor aggregate. Agriculture, Vol. 8(10), 2018, 151.

[7] Василенко П.М.Введениевземледельческуюмеханику(Introduction to agricultural mechanics), Киев: Сельхозобразование, 1996,252 p.

[8] Bhatia, Nam Parshad; Szegö, Giorgio P. Stability theory of dynamical systems. Springer. 2002. ISBN 978-3-540-42748-3

[9] Bhatia, N.P., Szegő, G.P.Stability Theory of Dynamical Systems. Springer: Heidelberg, Germany, 2002, 978-3-540-42748-3

[10]ГОСТ 20915-11. Техника сельскохозяйственная. Методы определения условий испытаний. (Agriculturalmachinery. Methods for the determination of the test conditions), Москва, 2011. $34 \mathrm{p}$;

[11]ГОСТ 24055-2016. Техника сельскохозяйственная. Методы эксплуатационнотехнологической оценки (Agriculturalmachinery. Methods of operational and technological assessment),Москва, 2018, 24 p.;

[12] Доспехов Б.Методика полевого опыта (Methodology of a field experiment). Москва, 2012, $352 \mathrm{p}$;

[13] Bulgakov V., Ivanovs S., Adamchuk V., Ihnatiev Y. Investigation of the influence of the parameters of the experimental spiral potato heap separator on the quality of work. Agronomy Research, Vol. 15(1), 2017, p. 44-54.

[14] Smith D.W., Sims B.G., O'Neill D.H. Testing and evalution of agricultural machinery and equioment. FAO Agricultural services bulletin, No 110, 1994, 288 p. 